http://jmscr.igmpublication.org/home/ ISSN (e)-2347-176x ISSN (p) 2455-0450 crossref DOI: https://dx.doi.org/10.18535/jmscr/v8i5.19

\title{
A Rare Case Report of Fractured Intraocular Lens Following Cow Horn Injury
}

\author{
Authors \\ Madhvendra Singh Ahirwar ${ }^{1}$, Tanmay Srivastav ${ }^{2 *}$, Rajendra Prakash Maurya ${ }^{3}$, \\ Virendra Pratap Singh ${ }^{4}$ \\ ${ }^{1}$ Junior Resident Regional Institute of Ophthalmology Banaras Hindu University Varanasi \\ ${ }^{2}$ Senior Resident Regional Institute of Ophthalmology Banaras Hindu University Varanasi \\ ${ }^{3}$ Assistant Professor Regional Institute of Ophthalmology Banaras Hindu University Varanasi \\ ${ }^{4}$ Professor Regional Institute of Ophthalmology Banaras Hindu University Varanasi \\ *Corresponding Author \\ Dr Tanmay Srivastav \\ Regional Institute of Ophthalmology, Banaras Hindu University, Varanasi, India
}

\begin{abstract}
Pseudophacocele is defined as displacement of artificial lens which is implanted after cataract surgery in subconjunctival space. The number of cases reported worldwide is very less in number. This condition needs differentiation from phacocele. Blunt ocular trauma to post cataract surgery eyes can cause artificiallens dislodgement and fracture of inntraocular lens implant in subconjunctival space and other ocular regions.

Here we report a case of 40 year male who presented with complaints of diminution in vision, pain and redness in right eye following blunt trauma by cow's horn 15 days back. He had history of cataract extraction with intraocular lens implantation 5 years back. On ocular examination a posterior chamber intraocular lens was seen in the anterior chamber with a broken haptic which migrated into subconjunctival space in the perilimbal area supero-temporally. He was managed with IOL explantation with implantation of sclera fixated IOL and repair of scleral wound.

Keywords: Pseudophacocele, Cow Horn Injury, Manual SICS, IOL Displacement, Blunt Trauma.
\end{abstract}

\section{Introduction}

Blunt ocular trauma to post-cataract surgery eyes can cause artificial lens dislodgement in subconjunctival space, suprachoroidal space, vitreous cavity, anterior chamber or can even lead to expulsion of implant from the eyeball. ${ }^{[1-7]}$ Pseudophacocele is defined as displacement of artificial lens which is implanted after cataract surgery in subconjunctival space. The term "Pseudophacocele" was first coined by Biedner et $a l{ }^{[1]}$ in the year 1977. The number of cases reported worldwide is very less in number. This condition needs differentiation from phacocele which is defined as traumatic displacement of normal crystalline lens in subconjunctival sac. ${ }^{[8]}$ This condition is one of the emergency condition in ophthalmic science predisposing to development of endophthalmitis. ${ }^{[9]}$ Since the condition is very rare, sufficient data on visual status and outcomes in such subjects is very 
limited. However, early and timely intervention may improve visual outcomes in such patients. ${ }^{[9]}$

\section{Case Report}

40 year old male patient farmer by occupation came to us in our department with complaint of diminution in vision, pain and redness in his right sided eye following blunt trauma bycow's horn 15 days back. He consulted a local practitioner in rural centre who prescribed him topical antibiotic and steroid eye drops along with topical atropine and intraocular pressure lowering drugs. His pain and redness got relieved but diminution of vision persisted for which he was referred to us at an advanced centre. His old records revealed complete hyphaema on first day after injury which resolved with above medications within one week. The time when he presented in our department he was using steroid eye drops and atropine topically. He gave history of extracapsular cataract surgery with posterior chamber PMMA lens implantation intraocularly (PCIOL) 5 years back in a Government hospital. On ocular examination his visual status was hand movement near face with perception of light and accurate projection of raysin all four quadrants in his right eye and 20/20 in left eye. The conjunctiva appeared to be congested mildly in affected eye. A PC-IOL was seen in chamber anteriorly with a broken haptic which migrated into subconjunctival space in the perilimbal area supero-temporally. (Figure 1) The cornea was apparently clear with normal sheen. The pupil was U-shaped due to absence of iris in superior quadrant. Vitreous strands were present in anterior chamber. Intraocular pressure in traumatized eye was six $\mathrm{mm} \mathrm{Hg}$ and in left eye was sixteen $\mathrm{mm} \mathrm{Hg}$ as recorded by Non Contact Tonometer. Anterior and posterior segment evaluation in nontraumatized eye showed unremarkable findings. Globe was in hypotony in right eye. Fundus examination by direct Ophthalmoscopyat a distance of one arm revealed a hazy media in right eye. Direct Ophthalmoscopyvia aphakic part showed normal disc findings and scarring at macula. Slit lamp fundus examination with $78 \mathrm{D}$ lens revealed mild vitritis. Indirect Ophthalmoscopy showed normal peripheral fundus. B scan Ultrasonography of affected eye reported mildly increased frequency suggestive of vitreous inflammation. Subsequently patient underwent conjunctival peritomy with removal of haptic and PCIOL. Vitrectomy was done anteriorly and sclera was sutured with absorbable vicryl sutures. Anatomical integrity of eye was restored by formation of chamber. Vision got improved to finger counting at 3 meters. Vitreous was not incarcerated in the wound. After 6 weeks patient underwent sclera fixation of IOL along with vitrectomy through pars plana route in second sitting. The patient's visual condition came upto to $6 / 36$ in right eye after 6 months of follow up. The intraocular pressure was $12 \mathrm{~mm} \mathrm{Hg}$ at previous visit and fundus revealed mild disc pallor with vertical $\mathrm{C}: \mathrm{D}$ ratio of 0.3 and macular scarring.

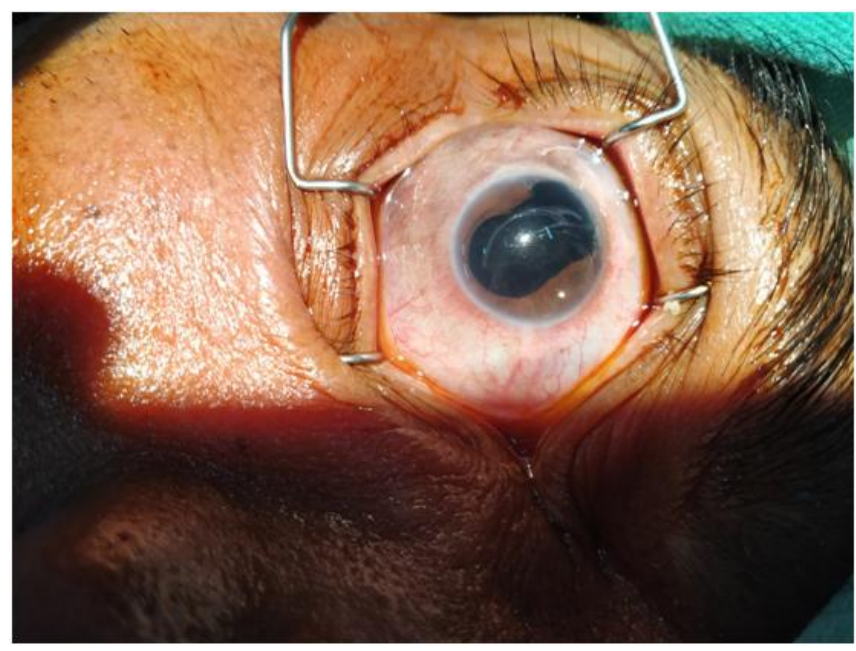

Figure 1 Figure Showing IOL in Subconjunctival Space with A U Shaped Pupil

\section{Discussion}

Biedner et al. was first to describe the term Pseudophacocele in a case with iris lens implant in 1977. ${ }^{[1]}$ Blunt trauma rarely causes subconjunctival displacement of IOL in post cataract surgery patients. Identification of dislocated IOL can be done by slit- lamp examination, fundoscopy, ultrasonography Bscan and ultrasound biomicroscopy (UBM). ${ }^{[1-4,10-}$ 13] Although ultrasound B- scan and UBM are 
contraindicated in open globe injuries as they carry risk of intraocular infection and bulging outwards of ocular contents, ${ }^{[14,15]}$ extensive subconjunctival bleed with or without uveal tissue covering displaced IOL and hyphema challenges the diagnosis in slit- lamp examination. This makes ultrasound a useful tool in diagnosis of displaced IOL. The cause encountered most frequently of pseudophacocele is blunt trauma. ${ }^{[11-}$ 13]

Though self- sealing sclero-corneal tunnel is stronger than sutured limbal wound as shown in various studies, ${ }^{[16]}$ in cases of patients who have used steroids for long duration postoperatively or in poor wound construction self-sealing tunnel remains weak. Large wounds with premature entry or deep tunnel if left unsutured poses risk of defective healing even after a long time after surgery following manual SICS. Hence in these cases, sutures should be placed so that such potential vision threatening conditions can be stopped from occurence.

The management of this condition depends on various factors such as time of reporting, visual acuity, presence of inflammation or infection, iris status, posterior capsule status, status of posterior capsule, vitreous status, and associated detachment of retina. ${ }^{[10,11,17,18]}$ Several studies propose good visual prognosis after aphakic correction, IOL implantation after vitrectomy or primary repair. ${ }^{[1,2,4,5,11]}$ It is mandatory to extract the IOL which has been displaced and repair sclera so that endophthalmitis can be prevented. Broken IOL or its haptic if left as such subconjunctivally may lead to erosion of sclera and perforation of globe. The main aim should be restoration of eyeball integrity. Narang et. al published good visual recovery in three out of five cases in his study in which they performed vitrectomyvia pars plana approach followed by glued IOL implant. ${ }^{[9]}$ This management is not possible in patients who present late to an ophthalmologist.

\section{Acknowledgements}

Dr. Sarangpani Sharan, Dr. Anurag Kashyap, Dr. Abhishek Kumar

\section{Author Declaration}

There is no any conflict of interest. There is no any source of funding.

\section{References}

1. Biedner, B., Rothkoff, L. \& Blumenthal, M. (1977). Subconjunctival dislocation of intraocular lens implant. Am J Ophthalmol; 84: 265-6.

2. Bene, C. \& Kranias, G. (1985). Subconjunctival dislocation of a posterior chamber intraocular lens. Am J Ophthalmol; 99: 85-6.

3. Foster, J. A., Lam, S., Joondeph, B. C. \& Sugar, J. (1990). Suprachoroidal dislocation of a posterior chamber intraocular lens. Am J Ophthalmol; 109: 731-2.

4. Sandramouli, S., Kumar, A., Rao, V. \& Khosla, A. (1993). Subconjunctival dislocation of posterior chamber intraocular lens. Ophthalmic Surg; 24,:770-1.

5. Kumar, A., Nainiwal, S. K., Dada, T. \& Ray, M. (2002). Subconjunctival dislocation of an anterior chamber intraocular lens. Ophthalmic Surg Lasers; 33,:319-20.

6. Chandravanshi, S. L., Dwivedi, A., Tirkey, E. R. \& Choudhary, P. (2015). Golden half ring sign for identification of pseudophacocele. Indian J Ophthalmol; 63: 259-61. 10.4103/0301-4738.156931

7. Bawankar, P., Lahane, T. \& Parekh, R. (2018). Pseudophacocele. Indian J Ophthalmol: 661191. 10.4103/ijo.IJO_323_18.

8. Bhattacharjee, K., Bhattacharjee, H., Deka, A. \& Bhattacharyya, P. (2007). Traumatic phacocele: Review of eight cases. Indian J Ophthalmol; 55: 466-468. 
9. Narang, P. \&Agarwal, A. (2017). Clinical outcomes in traumatic pseudophacocele: A rare clinical entity. Indian J Ophthalmol; 65: 1465-1469. 10.4103/ijo.IJO_1068_17

10. Bolling, J. P., Magargal, L. E., Shakin, E., Annesley, W. H., Jr., Sarin, L. K., Federman, J. \& Robb-Doyle, E. (1986). Trauma to eyes containing posterior chamber lenses. Trans $\mathrm{Pa}$ Acad Ophthalmol Otolaryngol; 38: 307-10.

11. Bandyopadhyay R, Banerjee A, Bhaduri G, Singh M. Traumatic pseudophacocele. J Indian Med Assoc 2004;102:731.

12. Mandal AK, Anand R. Traumatic pseudophacocele. Indian $\mathrm{J}$ Ophthalmol 2003; 51:177- 8 .

13. Joshi RS. Sub- conjunctival dislocation of posterior chamber intra- ocular lens: Five years after manual, small- incision cataract surgery. Nepal J Ophthalmol 2014;6:91- 4.

14. Kubal WS. Imaging of orbital trauma. Radiographics 2008;28:1729- 39.

15. Correa ZM, Augsburger JJ. Ultrasound biomicroscopy of the anterior ocular segment. Duane's foundations of clinical ophthalmology on CD- Rom. In: Foundations. Vol. 2, Ch. 106. Philadelphia: Lippincott Williams and Wilkins; 2006.

16. Mackool R, Russell R. Strength of clear corneal incisions in cadaver eyes. $J$ Cataract Refract Surg 1996; 22:721-5.

17. Agrawal, R., Wei, H. S. \& Teoh, S. (2012). Predictive factors for fi nal outcome of severely traumatized eyes with no light perception. BMC Ophthalmol; 12: 16. 10.1186/1471-2415-12-16

18. Rao, L. G., Ninan, A. \&Rao, K. A. (2010). Descriptive study on ocular survival, visual outcome and prognostic factors in open globe injuries. Indian J Ophthalmol; 58: 321-3. 10.4103/0301-4738.64116. 